\title{
Sistem Informasi Pencatatan Buku Tabungan Siswa Berbasis Web di Madrasah Ibtidaiyah Daroyissalam Desa Kertosono Kecamatan Sidayu Kabupaten Gresik
}

\author{
Nia Silfiyanti ${ }^{1}$, Khabibatul Anif ${ }^{2}$, Faridatun Nadziroh $^{3}$ \\ Program Studi Otomasi Perkantoran Akademi Komunitas Semen Indonesia - Gresik \\ Email: ${ }^{1}$ niasilfiyanti007@gmail.com, ${ }^{2}$ annifzalwa99@gmail.com ${ }^{3}$ faridatun.nadziroh@gmail.com
}

\begin{abstract}
Abstrak: Pada pengelolaan data tabungan siswa di Madrasah Ibtidaiyah Daroyissalam Desa Kertosono, Kecamatan Sidayu, masih terdapat kekurangan yakni penyimpanan yang masih belum terorganisir dan belum terintegerasi dengan sistem. Oleh sebab itu, jika terjadi masalah pencatatan data maka harus melakukan pengecekan ulang secara terus menerus untuk menghindari kesalahan yang fatal. Dengan merancang serta membangun sistem informasi pencatatan buku tabungan siswa berbasis web di MI Daroyissalam yang bertujuan untuk meningkatkan keefektifan dan keefisienan pada saat pencarian, pembuatan, dan penyimpanan data tabungan siswa di MI Daroyissalam. Dalam perancangan sistem informasi pencatatan tabungan siswa berbasis web di MI Daroyissalam, penulis menggunakan metode waterfall serta pemodelan flowchart dan diuji dengan metode pengujian blackbox. Pada penelitian ini menghasilkan sistem informasi pencatatan buku tabungan berbasis web di MI Daroyissalam dapat meningkatkan 90\% keefektifan dan keefisienan dalam pencarian, pembuatan, serta penyimpanan data tabungan siswa.
\end{abstract}

Kata Kunci: Tabungan, Sistem Berbasis Web, PHPRunner, SQLYog

\begin{abstract}
In managing student savings data at Madrasah Ibtidaiyah Daroyissalam Kertosono, Kec. Sidayu, there are still shortcomings namely storage that is still not organized and has not been integrated with the sistem. Therefore, if there is a problem in recording data, it is necessary to continuously re-check to avoid fatal errors. By designing and building a web-based student savings book recording information sistem at MI Daroyissalam which aims to improve the effectiveness and efficiency when searching, creating and storing student savings data at MI Daroyissalam. In designing a web-based student savings information recording sistem at MI Daroyissalam, the author uses the waterfall method and flowchart modeling and is tested with the blackbox testing method. The conclusion of this final report is that the web-based savings book information sistem at MI Daroyissalam can increase $90 \%$ effectiveness and efficiency in searching, creating and storing student savings data.
\end{abstract}

Keywords: Savings, Web-Based Sistem, PHPRunner, SQLYog

\section{PENDAHULUAN}

Institusi sekolah merupakan tempat untuk membentuk serta mendidik generasi penerus bangsa, tetapi kebanyakan permasalahan pada generasi penerus bangsa ini sebagian dari mereka sulit untuk menyisihkan sebagian uang saku, dikarenakan beberapa hal misalnya mereka tidak tahu bagaimana cara aman untuk menyimpan uang tersebut, niat sudah disisihkan tetapi diambil lagi untuk jajan atau yang lain. [1]

MI. Daroyissalam kertosono Kec. Sidayu Kab. Gresik yang bukan hanya merupakan satuan pendidikan dasar di bawah naungan Dinas Pendidikan Gresik.

Selain penyelenggaraan pendidikan MI. Daroyissalam Kertosono juga mengadakan programprogram lainnya yang sangat bermanfaat baik bagi kelangsungan sekolah, prestasi siswa maupun keuangan siswa, salah satunya adalah tabungan siswa. Salah satu peranan penting yang dirasakan adalah membantu pemerintah dalam mensukseskan program pendidikan tabungan dalam waktu tempuh satu tahun, dimana program tabungan ini membantu siswa yang kekurangan biaya untuk melanjutkan sekolah ke jenjang berikutnya.

Terdiri dari 6 Kelas yang yang terdiri dari satu angkatan satu kelas. Setiap awal Tahun pelajaran siswa dikasih buku tabungan baru dan dibagikannya hasil tabungan satu tahun kemarin. Dalam proses penyetoran tabungan siswa ini langsung menyetorkan buku tabungan ke bagian TU, untuk dicatat di buku tabungan per siswa dan ditulis di buku besar tabungan siswa yang dibuat untuk setoran kebagian bendahara tabungan. Adanya tabungan siswa ini untuk keperluan mendesak siswa dan pembiayaan sekolah misalnya yang selama ini berjalan digunakan untuk pembayaran buku LKS, Iuran komite sekolah, rencana study tour dan iuran lainnya. Dari sekolah dana tabungan siswa itu disimpan di Bank dua minggu sekali, setiap setoran ke Bank nominal yang dikumpulkan yaitu senilai IDR. 7.000.000.00.

Namun kendala sistem yang berjalan untuk pengelolaan tabungan siswa MI. Daroyissalam Kertosono saat ini masih dikerjakan secara manual, pencatatan dan penyimpanan data ditulis di buku, dan perhitungannya masih dikerjakan dengan alat bantu 
kalkulator. Dengan jumlah data yang banyak dan tidak tetap. Maka sistem tabungan ini kurang efektif dengan munculnya masalah-masalah sebagai berikut : Membutuhkan waktu untuk pencarian data siswa ketika memasukkan data transaksi penyetoran, dengan jumlah frekuensi transaksi yang banyak maka akan membutuhkan waktu yang relatif lama.

1. Jika terjadi masalah pencatatan data maka harus melakukan pengecekan ulang secara terus menerus untuk menghindari kesalahan yang fatal.

2. Harus melakukan perhitungan secara terus menerus jika dilakukan transaksi penyetoran maupun penarikan tabungan siswa.

Penelitian ini bertujuan membuat Sistem Informasi Pencatat Tabungan Siswa Berbasis Web di Desa Kertosono Kecamatan Sidayu Kabupaten Gresik dan memudahkan admin dalam menyelesaikan pekerjaan kantor. Penelitian dengan topik mengangkat sistem informasi pencatatan tabungan pernah dilakukan pada [1]-[3] dengan studi kasus yang berbeda-beda. Sedangkan penelitian sistem infromasi berbasis web pun juga pernah dilakukan oleh [8] dengan menggunakan metode WDLC (Web Development Life Cycle), yang mana sistem ini dapat memberikan solusi pada mitra untuk menangani transaksi tabungan.

Pada [5] juga membuat aplikasi iuran sekolah dengan metode dimulai dari observasi, wawancara, studi pustaka, analisis data dan sistem, dan pengujian. Metode pengujian ini dianggap efektif untuk penerapan aplikasi yang dibuat.

Selain itu, pada [6] dam [7] juga dibuat sistem informasi yang berkaitan dengan tabungan, dengan studi kasus yang berbeda. Dan sistem yang telah dibuat memang dapat memberikan solusi terbaik pada mitra.

Sehingga berdasarkan kebutuhan Madrasah Ibtidaiyah di Desa Kertosono Kecamatan Sidayu Kabupaten Gresik, yang membutuhkan sistem informasi tabungan dengan menggunakan metode yang sesuai dalam penyusunan sistem tersebut yang disebut SITASI (Sistem Informasi Pencatatan Tabungan Siswa) yang berbasis Web.

\section{METODE PENELITIAN}

Metode penelitian yang digunakan adalah Waterfall, yang dimulai dari tahapan sebagai berikut:

1. Requirement (Identifikasi), tahapan ini meliputi wawancara, observasi, dan studi pustaka.

2. Design (Perancangan Sistem)

Pada tahapan ini, penulis merancang DFD (Data Flow Diagram), Flowmap, dan Struktur Tabel Database. DFD dapat dilihat pada Gambar 1.

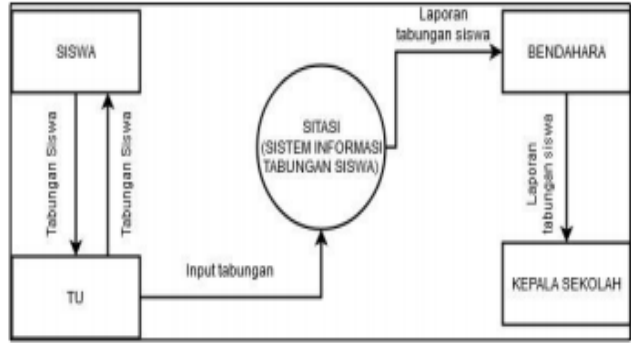

Gambar 1. Data Flow Diagram

Sedangkan FLowmap ditunjukkan pada Gambar 2.

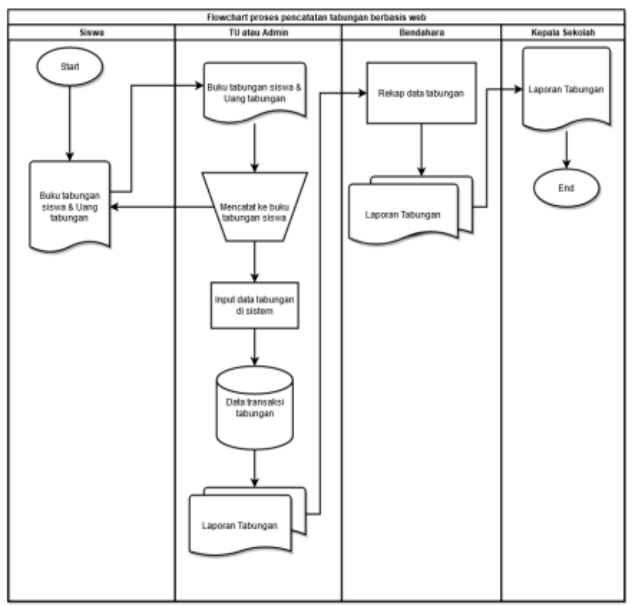

Gambar 2 Flowmap Sistem

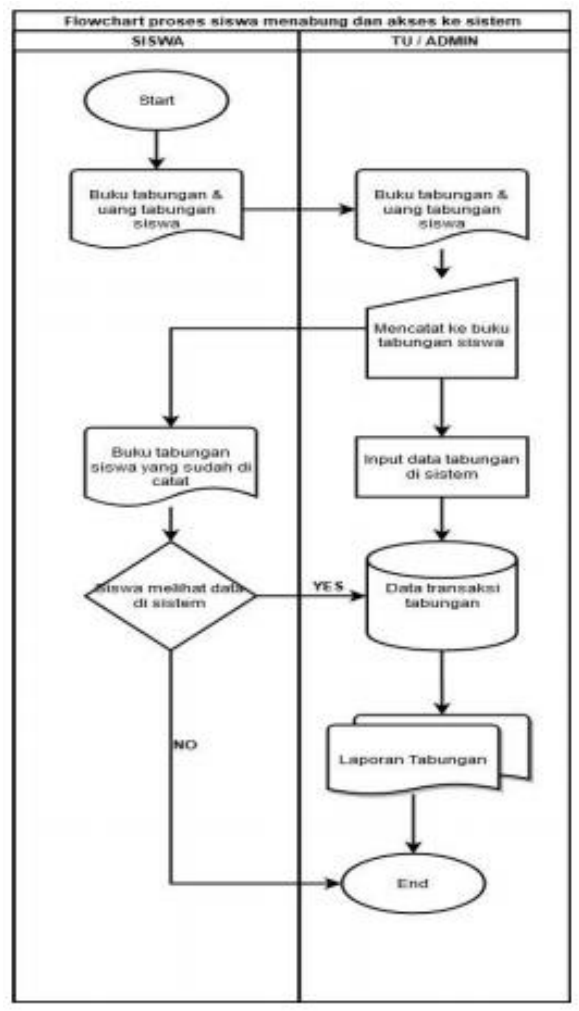

Gambar 3 Flowchart Siswa Menabung Ke TU

Flowmap pada Gambar 2 terdiri dari beberapa proses flowchart yaitu: Flowchart proses siswa menabung ke bagian admin atau TU dan dapat mengakses sistem pada 
Gambar 3. Flowchart proses bagian admin atau TU menerima tabungan dari siswa, dan menginput data ke sistem dan tabungan siswa ditunjukkan pada Gambar 4. Flowchart proses Bendahara sekolah merekap keuangan tabungan siswa pada Gambar 5. Proses Kepala Sekolah Melihat Laporan pada Gambar 6.

\section{Impelementasi Sistem}

Implementasi sistem adalah tahap penerapan sistem yang akan dilakukan jika sistem disetujui termasuk program yang telah dibuat pada tahap perancangan sistem agar dapat dioperasikan. Implementasi sistem informasi pencatatan tabungan berbasis web ini, penulis menggunakan bahasa pemrograman PHP dengan basis data MySQL. Rancangan Antar Muka (User Interface) merupakan mekanisme komunikasi antara pengguna (user) dengan sistem. Rancangan ini dapat menerima informasi dari pengguna (user) dan memberikan informasi kepada pengguna (user) untuk membantu mengerahkan alur penelusuran masalah hingga menemukan solusi.

\section{Verification (Pengujian Sistem)}

Integrasi dan pengujian sistem merupakan teknik pengujian untuk mengungkap kesalahan pada sistem. Integrasi pada penelitian ini, dilakukan dengan pendekatan top-down terhadap struktur program. Sistem diintegrasikan dengan menggerakkan ke bawah melalui hirarki kontrol yang dimulai dari menu utama. Menurut [4], pengujian sistem merupakan elemen kritis dari jaminan kualitas perangkat lunak dan merepresentasikan kajian pokok dari spesifikasi, desain dan pengkodean. Dalam penelitian ini rancangan pengujian sistem dilakukan dengan melakukan pengujian black-box terhadap semua fungsi dalam aplikasi. Pengujian blackbox merupakan salah satu pengujian aplikasi atau perangkat lunak yang berfokus pada persyaratan fungsional perangkat lunak. Karena itu uji coba blackbox memungkinkan pengembang software untuk membuat himpunan kondisi input yang akan melatih seluruh syarat-syarat fungsional suatu program.

\section{Maintenance (Pemeliharaan Sistem)}

Pada dasarnya tahapan ini merupakan tahap yang membutuhkan waktu paling lama diantara semua tahapan. Tahapan ini merupakan tahap penggunaan sistem oleh pengguna. Pengguna akan mengetahui hasil dari sistem yang telah diinginkan. Setelah itu, dilakukan tahap perawatan atau maintenance. Pemeliharaan suatu software diperlukan, termasuk di dalamnya adalah pengembangan, karena software yang dibuat tidak selamanya hanya seperti itu. Ketika dijalankan mungkin saja masih ada permasalahan yang tidak ditemukan sebelumnya, atau ada penambahan fitur-fitur yang belum ada pada software tersebut.

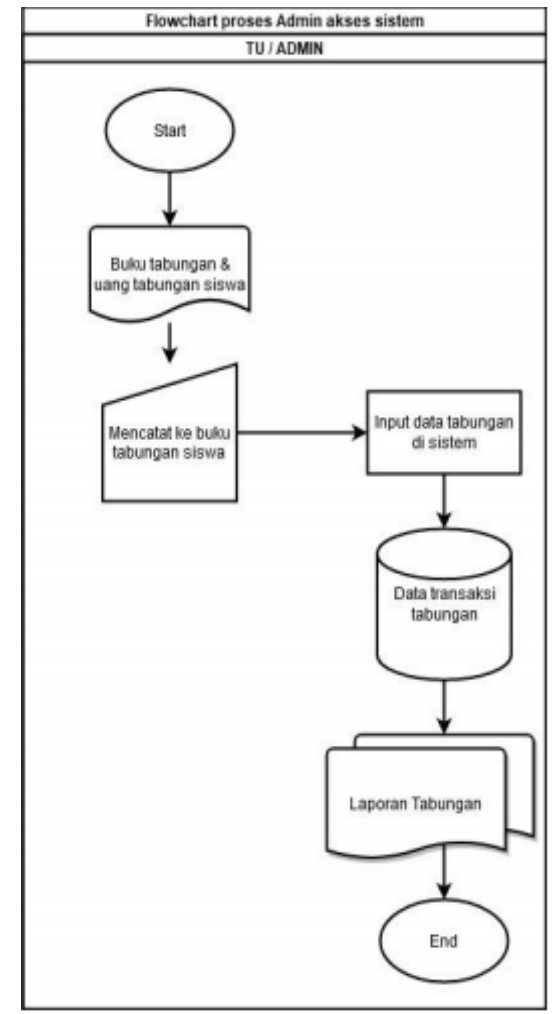

Gambar 4 Flowchart TU Menerima Tabungan

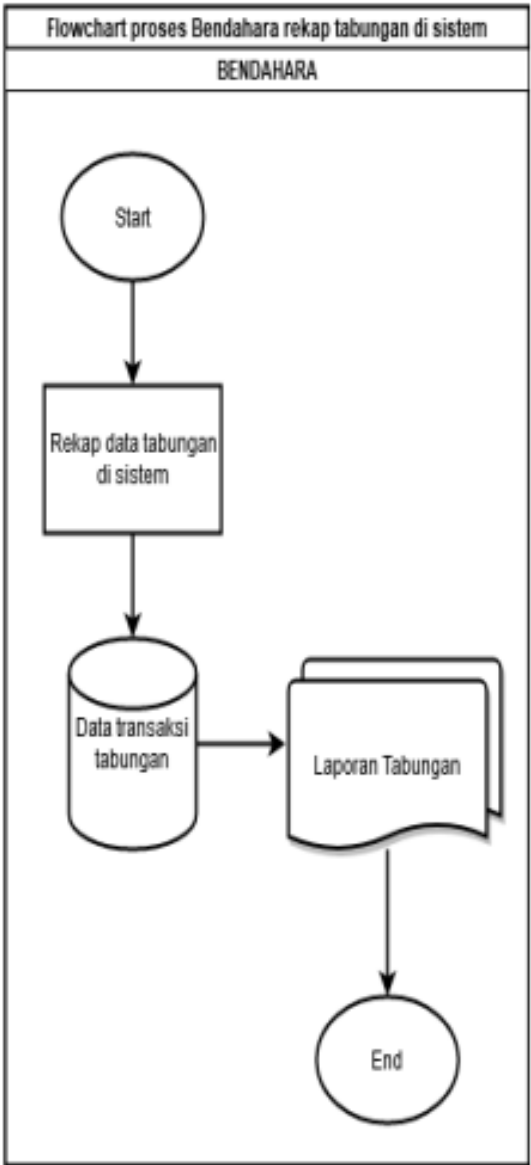

Gambar 5 Flowchart Bendahara Membuat Laporan 


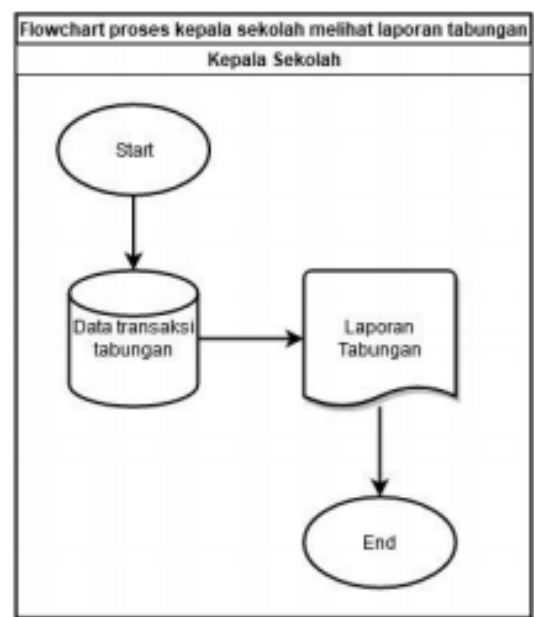

Gambar 6 Flowchart Kepala Sekolah Melihat Laporan

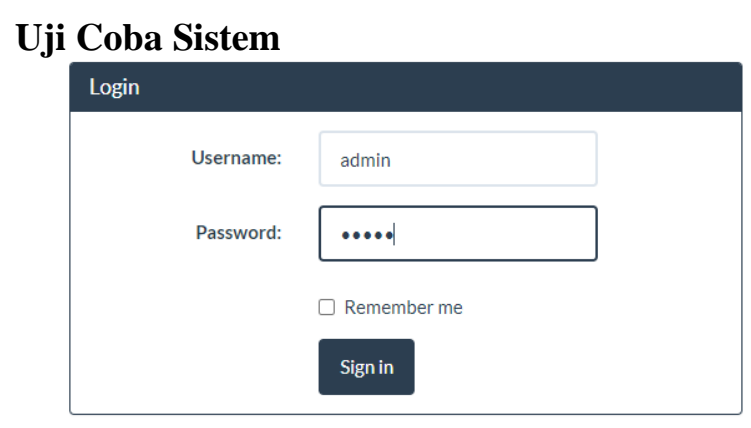

SIPKAN - Copyright 2020

Gambar 7 Halaman Login

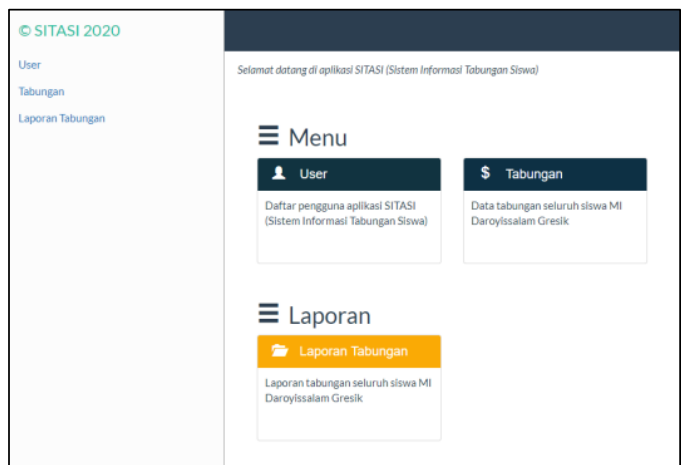

Gambar 8 Tampilan Menu Utama

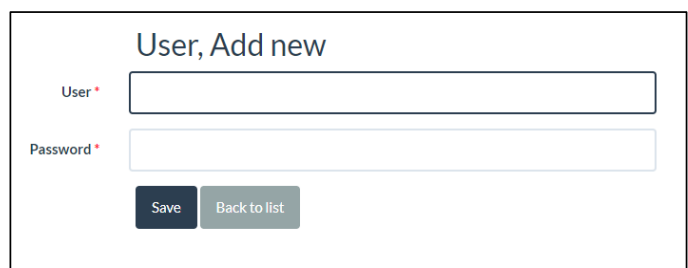

Gambar 9 Tampilan Penambahan User

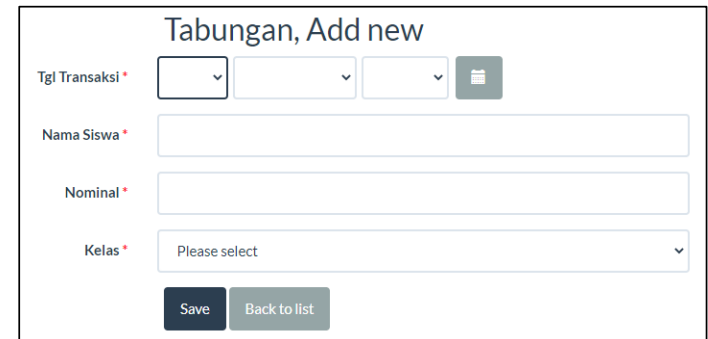

Gambar 10 Tampilan penambahan data tabungan

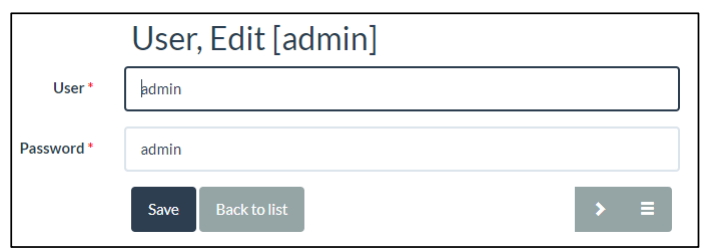

Gambar 11 Tampilan Edit User

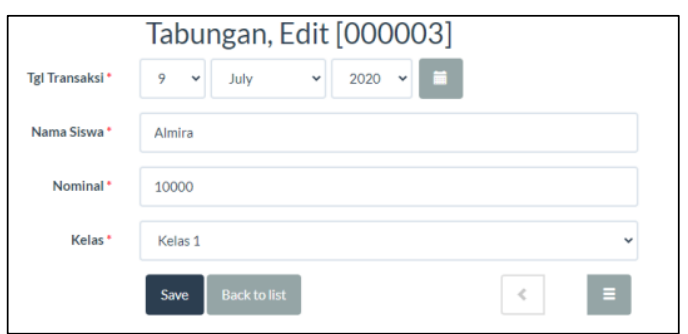

Gambar 12 Tampilan Edit Tabungan

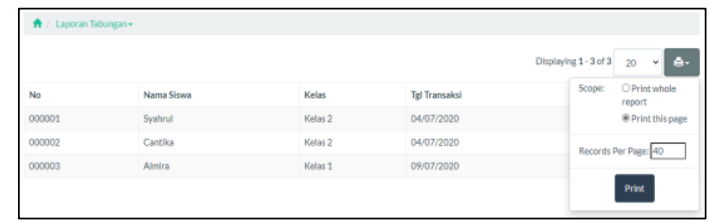

Gambar 13 Tampilan Cetak Tabungan

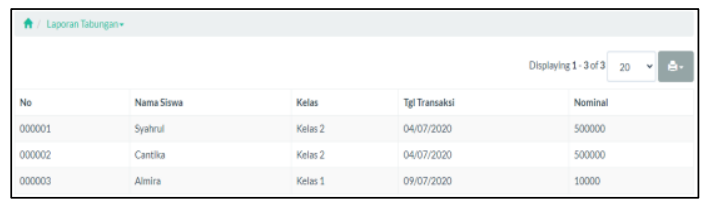

Gambar 14 Tampilan Laporan Tabungan

\section{HASIL DAN PEMBAHASAN}

Dalam penelitian ini rancangan pengujian sistem dilakukan dengan melakukan pengujian black-box terhadap semua fungsi dalam aplikasi. Pengujian blackbox merupakan 35 salah satu pengujian aplikasi atau perangkat lunak yang berfokus pada persyaratan fungsional perangkat lunak. Karena itu uji coba blackbox memungkinkan pengembang software untuk membuat himpunan kondisi input yang akan melatih seluruh syarat-syarat fungsional suatu program. 
Tabel 1 Pengujian Login Admin Data Normal

\begin{tabular}{|l|l|l|l|}
\hline \multicolumn{4}{|c|}{ Kasus dan Hasil Uji (Data Normal) } \\
\hline \multicolumn{1}{|c|}{ Data } & \multicolumn{1}{|c|}{ Hasil } & \multicolumn{1}{c|}{ Pengamatan } & \multicolumn{1}{c|}{ Kesimpulan } \\
\hline $\begin{array}{l}\text { Username : } \\
\text { admin } \\
\text { Password : } \\
\text { adminmaster }\end{array}$ & $\begin{array}{l}\text { Tercantum pada } \\
\text { textview } \\
\text { username dan } \\
\text { password }\end{array}$ & $\begin{array}{l}\text { Dapat mengisi } \\
\text { login sesuai harapan }\end{array}$ & [x] Diterima \\
\hline $\begin{array}{l}\text { Klik tombol } \\
\text { Login }\end{array}$ & Login berhasil & $\begin{array}{l}\text { Tombol login } \\
\text { dapat ber- } \\
\text { fungsi sesuai } \\
\text { harapan }\end{array}$ & [x] Diterima \\
\hline
\end{tabular}

Tabel 2 Pengujian Login Admin Data Salah

\begin{tabular}{|c|c|c|c|}
\hline \multicolumn{4}{|c|}{ Kasus dan Hasil Uji (Data Salah) } \\
\hline $\begin{array}{c}\text { Data } \\
\text { Masukan }\end{array}$ & Hasil & Pengamatan & Kesimpulan \\
\hline $\begin{array}{l}\text { Username : } \\
\text { Admin } \\
\text { Password : } \\
\text { Adminmaste } \\
r\end{array}$ & $\begin{array}{l}\text { Tercantum pada } \\
\text { textview } \\
\text { username dan } \\
\text { password }\end{array}$ & $\begin{array}{l}\text { Dapat mengisi } \\
\text { login sesuai } \\
\text { harapan }\end{array}$ & $\begin{array}{l}\text { [x] Diterima } \\
\text { [ ] Ditolak }\end{array}$ \\
\hline $\begin{array}{l}\text { Klik tombol } \\
\text { Login }\end{array}$ & $\begin{array}{l}\text { Tidak dapat } \\
\text { login }\end{array}$ & $\begin{array}{l}\text { User tidak dapat } \\
\text { login dan tampil } \\
\text { pesan "invalid } \\
\text { login" }\end{array}$ & $\begin{array}{l}\text { [x] Diterima } \\
\text { [ ] Ditolak }\end{array}$ \\
\hline
\end{tabular}

Tabel 3 Pengujian Penginputan Data Tabungan Data Normal

\begin{tabular}{|l|l|l|l|}
\hline \multicolumn{4}{|c|}{ Kasus dan Hasil Uji (Data Normal) } \\
\hline Data Masukan & \multicolumn{1}{|c|}{ Hasil } & Pengamatan & $\begin{array}{l}\text { Kesimp } \\
\text { ulan }\end{array}$ \\
\hline $\begin{array}{l}\text { Data-data } \\
\text { tabungan siswa }\end{array}$ & $\begin{array}{l}\text { Input data } \\
\text { tabungan } \\
\text { dengan benar } \\
\text { dan lengkap }\end{array}$ & $\begin{array}{l}\text { Input data } \\
\text { dilakukan } \\
\text { dengan benar } \\
\text { dan lengkap }\end{array}$ & $\begin{array}{l}{[\mathrm{x}]} \\
\text { Diterima } \\
{[\text { ] ] }} \\
\text { Ditolak }\end{array}$ \\
\hline
\end{tabular}

Tabel 4 Pengujian Penginputan Data Tabungan Data Salah

\begin{tabular}{|l|l|l|l|}
\hline \multicolumn{4}{|c|}{ Kasus dan Hasil Uji (Data Salah) } \\
\hline $\begin{array}{c}\text { Data } \\
\text { Masukan }\end{array}$ & \multicolumn{1}{|c|}{ Hasil } & \multicolumn{1}{|c|}{ Pengamatan } & Kesimpulan \\
\hline $\begin{array}{l}\text { Input data } \\
\text { tabungan }\end{array}$ & $\begin{array}{l}\text { Menampilkan } \\
\text { Pesan "Required } \\
\text { Field" }\end{array}$ & $\begin{array}{l}\text { Penyimpanan } \\
\text { tidak dapat } \\
\text { dilakukan dan } \\
\text { tampil pesan } \\
\text { "Required } \\
\text { Field" }\end{array}$ & [x] Diterima \\
& [ ] Ditolak \\
\hline $\begin{array}{l}\text { Klik tombol } \\
\text { Simpan }\end{array}$ & $\begin{array}{l}\text { Data tidak } \\
\text { tersimpan pada } \\
\text { tabel tabungan }\end{array}$ & $\begin{array}{l}\text { Tidak dapat } \\
\text { melakukan } \\
\text { penyimpanan } \\
\text { pada tabel } \\
\text { tabungan }\end{array}$ & [ [ ] Ditolak \\
\hline
\end{tabular}

Tabel 5 Pengujian Laporan

\begin{tabular}{|c|l|l|l|}
\hline \multicolumn{4}{|c|}{ Kasus dan Hasil Uji (Data Normal) } \\
\hline $\begin{array}{c}\text { Data } \\
\text { Masukan }\end{array}$ & \multicolumn{1}{|c|}{ Hasil } & \multicolumn{1}{|c|}{ Pengamatan } & Kesimpulan \\
\hline Laporan & $\begin{array}{l}\text { Pencarian data } \\
\text { yang } \\
\text { tersimpan } \\
\text { dalam } \\
\text { datahase }\end{array}$ & $\begin{array}{l}\text { Pencarian data } \\
\text { dapat dilakukan } \\
\text { dengan benar dan } \\
\text { tepat }\end{array}$ & [x] Diterima \\
[ ] Ditolak \\
\hline
\end{tabular}

Tabel 6 Pengujian Input Data User Data Normal

\begin{tabular}{|l|l|l|l|}
\hline \multicolumn{4}{|c|}{ Kasus dan Hasil Uji (Data Normal) } \\
\hline Data Masukan & \multicolumn{1}{|c|}{ Hasil } & \multicolumn{1}{c|}{ Pengamatan } & Kesimpulan \\
\hline $\begin{array}{l}\text { Data-data user } \\
\text { lengkap }\end{array}$ & $\begin{array}{l}\text { Input data } \\
\text { user } \\
\text { dengan benar } \\
\text { dan lengkap }\end{array}$ & $\begin{array}{l}\text { Input data } \\
\text { dilakukan } \\
\text { dengan benar dan } \\
\text { lengkap }\end{array}$ & [ ] ] Ditolak \\
\hline $\begin{array}{l}\text { Klik tombol } \\
\text { Simpan }\end{array}$ & $\begin{array}{l}\text { Data dapat } \\
\text { tersimpan di } \\
\text { tabel user }\end{array}$ & $\begin{array}{l}\text { Dapat melakukan } \\
\text { penyimpanan data } \\
\text { user }\end{array}$ & {$\left[\begin{array}{l}\text { [ ] Diterima } \\
\text { [ ] Ditolak }\end{array}\right.$} \\
\hline
\end{tabular}

Tabel 7 Pengujian Penginputan Data User Data Salah

\begin{tabular}{|l|l|l|l|}
\hline \multicolumn{4}{|c|}{ Kasus dan Hasil Uji (Data Salah) } \\
\hline $\begin{array}{c}\text { Data } \\
\text { Masukan }\end{array}$ & \multicolumn{1}{|c|}{ Hasil } & Pengamatan & Kesimpulan \\
\hline $\begin{array}{l}\text { Input data } \\
\text { user }\end{array}$ & $\begin{array}{l}\text { Menampilkan } \\
\text { Pesan } \\
\text { "Required } \\
\text { Field" }\end{array}$ & $\begin{array}{l}\text { Penyimpanan } \\
\text { tidak dapat } \\
\text { dilakukan, } \\
\text { tampil pesan } \\
\text { "Required } \\
\text { Field" }\end{array}$ & [x] Diterima \\
\hline $\begin{array}{l}\text { Klik tombol ] Ditolak } \\
\text { Simpan }\end{array}$ & $\begin{array}{l}\text { Data tidak } \\
\text { tersimpan } \\
\text { pada tabel } \\
\text { user }\end{array}$ & $\begin{array}{l}\text { Tidak dapat } \\
\text { melakukan } \\
\text { penyimpanan } \\
\text { pada tabel user }\end{array}$ & [ [ ] Ditolak \\
\hline
\end{tabular}

\section{KESIMPULAN}

Berdasarkan hasil observasi, perancangan, ujicoba, dan analisa yang telah dilakukan mengenai sistem ini, penulis mendapatkan beberapa kesimpulan sebagai berikut :

1. SITASI merupakan sebuah sistem informasi berbentuk digital perkantoran meliputi pencatatan tabungan siswa di MI Daroyissalam

2. Sistem ini dibangun dengan menggunakan PHPRunners dengan bahasa pemograman PHP dan pengelolaan database menggunakan SQLYog

3. Fasilitas multiuser pada sistem SITASI dapat digunakan oleh beberapa pemakai/user namun untuk hak akses user ditentukan oleh Admin Master

\section{SARAN}

1. Agar pemanfaatan sistem lebih baik, sebaiknya untuk penelitian selanjutnya perlu pengembangan yang lebih lanjut mengenai fitur-fitur yang telah ada.

2. Sehubungan dengan perbaikan sistem, maka sistem ini yang telah dirancang khusus untuk mempermudahkan pekerjaan dapat dipelihara dengan baik dan dikembangkan sesuai kebutuhan yang ada.

3. Agar menjaga keamanan data yang tersimpan didalam database, perlu diadakan sinkronisasi database secara berkala

\section{DAFTAR PUSTAKA}

[1] Setyo Wibowo, L. (2015). Perancangan Sistem Pengolahan Data Tabungan Siswa Berbasis Web Di SDN 2 Temon Kec. Ngrayun Kab. Ponorogo. Tugas Akhir: Teknik Informatika. Universitas Muhammadiyah

[2] Darmawan, I. K. A. Y. (2017). Perancangan Sistem Informasi Simpan Pinjam Pada Primer Koperasi Kartika "Mawas" Berbasis Web. Tugas Akhir: Ilmu Komputer Universitas Pembangunan Nasional Veteran Jakarta

[3] Suwarto, S., Sany, N., \& Indriani, E. (2018). Sistem Informasi Tabungan Siswa Berbasis Web Pada Sekolah Menengah Kejuruan (SMK) Nusa Putra Kota Tangerang. Journal Sensi, vol 4, no 2, 244-256. 
[4] Wijaya, A., \& Harjuna, A. M. (2017). Perancangan Program Aplikasi Tabungan Menggunakan Server Nginx (Studi Kasus Madrasah Ibtidayah Negeri 01 Kota Bengkulu). Pseudocode, Vol. 4, no.1 ,hal 29-36.

[5] Puspitasari, R., Purnama, B. E., \& Iriani, S. (2013). Aplikasi Pembayaran Iuran Sekolah Dan Buku Lembar Kerja Siswa Pada Sekolah Menengah Atas Negeri 1 Punung. IJNSIndonesian Journal on Networking and Security, Vol 4, no 3, hal 1-7.

[6] Hapsari, S., \& Wardati, I. U. (2011). Rancang Bangun Sistem Informasi Pembayaran Dan Tabungan Siswa Pada Bank Mini Artha Mandiri Sekolah Menengah Kejuruan (SMK) Negeri Pringkuku Pacitan. Speed-Sentra Penelitian Engineering dan Edukasi, Vol. 3, no. 2, hal 5564

[7] Umpu, E. F. G. S. (2019). Rancang Bangun Sistem Informasi Akuntansi Pengelolaan Tabungan Siswa Pada Sd Ar-Raudah Bandar Lampung. Tugas Akhir. Sistem Informasi Akutansi. Univesitas Teknokrat.

[8] Triyanti, D., \& Dermawan, T. (2019). Membangun Sistem Informasi Pengolahan Data Tabungan Siswa Berbasis Web. Jurnal Informasi dan Komputer, Vol 7 No. 2, hal 109120. 